\title{
Better Benefits for Better Business: Certified Benefit Corporations Connected Through Internal Communications
}

\author{
Carly Adair ${ }^{1}$ and Holly Overton ${ }^{1}$ \\ ${ }^{1}$ University of South Carolina, Columbia, SC, USA
}

\begin{abstract}
Despite the broad body of research examining Corporate Social Responsibility (CSR) communications, there remains a lack of literature discussing the expansion of Certified Benefit Corporations (B Corps), which are businesses that meet a verified social and environmental performance to advance social good. Existing research analyzes the connection between internal communications and CSR. The following research reviews this relationship and suggests that more for-profit companies qualify to be effective B Corps due to shared qualitative characteristics of strong internal communications. The characteristics reviewed are corporate storytelling, triple bottom line values, and the importance of key decision-makers. The literature review connects CSR and internal communications to form the foundation of 21 interview questions. The interview questions identify the qualitative characteristics of B Corps through an in-depth interview process. Top key decision-makers in B Corps were selected to interview to gather qualitative information on the internal communications of their companies. The interview questions led to an open dialogue about the influence B Corps have on each company's internal structure. Each interview was transcribed accordingly and discussed in the research below. Three themes were discovered after reviewing the primary research. The consensus suggests that a sense of strong internal communications in a company is a demonstrated trait of a Certified Benefit Corporation, therefore encouraging an expansion of Certified Benefit Corporations for companies who already display strong internal communications.
\end{abstract}

\section{Introduction}

CSR (CSR) emerged from social responsibility, a concept where firms took on a professional model that ensured their company was being held accountable for their impact on society (Carroll, 1979). Milton Friedman once argued in a statement, "There is one and only one social responsibility of business, to increase its profits." Friedman explains that the act of business cannot equal true altruism, but CSR argues differently. In the following research, to measure internal communications, qualitative characteristics found common in for-profit businesses that value CSR are compared to Certified Benefit Corporations that value CSR to discuss the connection of strategies in internal communications that are credible to Certified Benefit Corporations.

Scholars have long argued that individuals' perceptions of a company's CSR, or how it contributes to societal good, impacts profits and reputation of a brand (Bowden, 2009). Recent studies indicate that more than 70\% of consumers were likely to purchase products from companies that have a deeper commitment to a cause-related campaign that they supported. Furthermore, $90 \%$ of respondents indicated that they would switch from well-known brands to the comparable one if the latter brand was associated with a good cause (Cone, 2006). Cone Communications conducted a nationwide survey that revealed that $89 \%$ of respondents would switch to a brand associated with a social cause given comparable price and quality, and $91 \%$ desire to see more brands contributing to social issues (Cone, 2013). 
These studies reveal that the consumer's perspective is an essential factor in the formation of brand values and sales. If around $89 \%$ of a for-profit consumer base purchases from brands who participate in CSR, then we can interpret that the overall perception and likability would benefit the sales of the brand if they participated in CSR. These statistics raise questions concerning the saturation of CSR in the future of business. Why wouldn't every brand participate in CSR if it is a direct increase of sales? Are companies using CSR to increase sales and not altruism? Are sustainable businesses just greenwashing consumers? How do we know the CSR is reliable? The answer to these questions relies on a credible source, this research specifically highlights efforts made by a nonprofit known as B Lab to provide credibility in businesses who participate in CSR.

B Lab, the nonprofit that created Certified Benefit Corporations as a new innovative business model, defines Certified Benefit Corporations (B Corps) as "a new kind of business that balances purpose and profit. They are legally required to consider the impact of their decisions on their workers, customers, suppliers, community, and the environment," (Certification, 2020, n.p.). The mission of B Corps aligns perfectly with CSR by definition. After the literature review, primary research was conducted to fill the gap of academic research around the relationship discussed. The following review discusses existing literature that correlates between internal communications and CSR, then to analyze the influence internal communications have had on Certified Benefit Corporations.

The following research reviews the relationship between internal communications of for-profit businesses and its participation in CSR to illustrate the effectiveness of B Corps. Scholars have found that companies with strong CSR have strong internal communications (Pompper, 2018). This correlation proposed by Pompper (2018) emphasizes the necessity of strong internal communications in an organization curated around the philosophy of CSR. According to Pompper (2018), companies with strong CSR have strong internal communications. This correlation emphasizes the necessity of strong internal communications in an organization curated around the philosophy of CSR, especially B Corps (Pompper, 2018).

\section{Literature Review}

When it comes to corporations, the way employees are treated is a reflection of how the business communicates internally and externally. The way companies organize themselves conveys signals about the company's participation in CSR. In internal communications, these signals are received by one of the most essential stakeholders, the employee. The following literature review provides information on previous research connecting the importance of CSR and internal communications.

\section{Corporate Storytelling in Internal Communications}

Employees seek identity with the company for which they are working (Ashforth \& Mael, 1989). If an employee is identifying with a company, they will adopt the attitudes and engage in the same behaviors that the corporation provides. People looking for part-time jobs, full time careers, and other forms of work gravitate toward companies they are attracted to if they have the privilege to do so. When an employee identifies with a brand, they are more likely to be an advocate for what the brand is an advocate for.

Corporate storytelling is a persuasive, natural, and simple way to communicate a message within a business. Corporate storytelling is the ideal way of making the employee a champion of your company (Duthler, G., \& Dhanesh, G. S., 2018). This combines preconceived ideas that the employee is satisfied. Satisfied employees are more likely to communicate with other employees as well as external audiences (Sarah Desirée Schaefer, Ralf Terlutter \& Sandra Diehl, 2019). If the workplace has a proper employment hierarchy, it would be enforced to have an overall encouraging employee attitude, so their behavior reflects your brand positively.

In a study that surveyed employees in the United Arab Emirates, they found that two-way symmetrical communication about CSR used to involve employees in dialogue interaction is the highest likely to predict employee 
engagement between corporations and stakeholders (Schaefer, Terlutter., \& Diehl, 2019). Two-way symmetrical communication is defined as the dialogue between the corporation and the stakeholders. The employee is a crucial stakeholder of a company as the beliefs of the employees are essentially free endorsements and exposure as well as an additional consumer (Duthler, G. \& Dhanesh, G. S., 2018). The more an employee is engaged, informed, and encouraged with the initiatives of CSR, the more likely they are to trust that their company is serving the greater community and is devoting time, money, and other resources to socially responsible causes.

\section{Triple Bottom Line in Internal Communications}

Sustainability is achieved without compromising the ability of future generations to meet their environmental, social, and economic needs with resources (Katz, 2019). Consumers worldwide are showing an interest in sustainability and these values are expressed in changes in purchasing behavior and expectations of giving back. This can be seen in the consumer behavior where they find firms with community involvement more trustworthy, likable, and prefer to purchase (Keller \& Aaker, 1998).

Sustainable enterprises represent an extension of CSR in which the firm commits in its model to having a minimal negative impact on the global or local environment, community, society, or economy. Companies have integrated the clarification of a value set in the mission and vision statements during the strategic planning process of a business model (Miller-Steven, 2018).

Sustainability has been a new trend in business, but powerhouse companies are adopting the same principles and applying them to all aspects of their brand. In recent articles, sustainability has been a key focus more than ever before concerning humanization and how people are treated. According to Benton, changing dominant parts of consumption might serve to change traditional inequalities, alienations, and discrimination. Especially in America, the system is bent out of sustainability, and we are slowly growing back (Benton, 2002). Benton was before his time in predicting Reformation's fall about sustainability. While they created wholesome clothes, the founder was outed stating ignorant social remarks in the 2020 Black Lives Matters movement (Mull, 2020). With a leader and claim to sustainability lacking social ethics, Reformation did not meet a combination of environmental, financial, and economical consciousness encompassing the triple bottom line. The triple bottom line is a value in a business model that can define mission statements and employee engagement. Numerous organizations have created their societal impact with a profitable business model while highlighting the triple bottom line, such as Seventh Generation, Patagonia, and DHL. As stated in the introduction, the consumer notices when a company encompasses areas of CSR, so a company with the ability to cover multiple branches, should. The triple bottom line is a goal for companies to meet who want to be transparent and credible for their diversity of sustainability.

\section{Key Decision Makers and Internal Communications}

Expenses for CSR have become the third-largest budget item for corporate communication departments in larger companies (Hutton, 2001). Time and money are precious values, if businesses direct their time and money to CSR then it is an obvious value of their business. Corporate operations are managed by Chief Executive Officers (CEOs) and other key decision-makers. The objectives for the executive positions are expressed in an owner's directive that may constitute limitations to work per the triple bottom line if it exclusively focused on the financial output and the interests of the shareholders (Elkington, 2004). This dimension comes with challenges where old ways of running a business are compared to the unknown path towards sustainability through CSR, yet change is inevitable, so CEOs and key decision-makers are often the spokespeople to relay this message to the public.

CEO activism is one-way organizations can communicate their internal communications to the public to display their internal value. CSR can often be used as a form of strategic communications (Chatterji, 2019). An ongoing and popular example of CSR is through TOMS. TOMS has a business model that revolves around giving back, the "One for One" campaign provides shoes for someone in need when one is purchased. TOMS has recently expanded to allow the user of the website to pick which charitable foundation their purchase goes to with their "Pick Your Style, Pick 
Your Give" campaign with options ranging from mental health awareness, women's rights, clean water initiatives, and many more. This form of CSR is typically known as cause-marketing as they are promoting a product or service with the initiative of giving back. Different ways CSR is chosen by the executives of a company to best fit their audience and because marketing is just the beginning.

According to public relations pioneer Ed Bernays, "public relations is the practice of social responsibility" (Pompper, 2018). In times when public relations practices are needed CSR is an incredible resource strategy. We often see key decision-makers as an asset during times of crisis, announcements, or any new changes to the brand. Having a positive internal relationship with key decision-makers in specific is crucial to the health of the perspective from the publics of your company.

\section{Certified Benefit Corporations}

Certified Benefit Corporations have displayed strong internal communications. As of August 2020, there are 3,445 Certified Benefit Corporations in 71 countries (Certification, 2020, n.p.). B Lab was founded in 2006 by the entrepreneurs behind AND1, a US sportswear company that was one of the earliest businesses with triple bottom line values (Giddens, 2019). The benefits of becoming a Certified Benefit Corporation go beyond donating funds to charity. In order to become a legally certified benefit corporation, a business must take an assessment that reviews certain aspects of the corporation such as the quality of the products and services, the internal communications, and how involved the business is with their community. A score of 80/200 or higher is necessary for certification. Certified Benefit Corporations pay an annual fee to legally bind them to the qualifications set in place by the B Lab based on their annual revenue. The fees go to the nonprofit B Lab, making certified benefit corporations a participant in CSR themselves.

According to B Lab, "Every 500 years or so, there is a tipping point in the evolution of capitalism. This is it, “(Singlebrook, 2019). Certain state legislation allows businesses of benefit corporations, sole proprietors, limited liability corporations, and other corporate structures to apply to become a B Corp. The application of the model provided by this legal binding is a title, and the B Lab that creates certification is the label given and must meet certain statutes of accountability, transparency, and performance (Storper, 2018). "B Corps and Benefit Corporations represent a new breed of conscious capitalism, combining higher purpose, accountability, and transparency where there's no trade-off between return on investment and social impact," Jonathan Storper, co-chair of the legal group who drafted benefit corporation legislation in California, said (Storper, 2018). Certified Benefit Corporations are the next step to publicly claiming CSR and general "good" for for-profit organizations. The internal communications of B Corps align similarly with those who simply participate in CSR.

\section{Corporate Storytelling in Certified Benefit Corporations}

Corporate storytelling is analyzed in the certified benefit corporation assessment. The assessment wants it to be clear that the corporation communicating to their employee's involvement with B Corps can eliminate misinformed employees (5 Business Management Strategies We Learned as a B Corp, 2018). Employees who understand the benefits of this addition can engage in the impact-focused language in marketing, help create goals for CSR initiatives, and be involved in dialogue (5 Business Management Strategies We Learned as a B Corp, 2018). Engaging employees in conversations about CSR has been proven to create corporate storytelling in companies, which is only enhanced with the addition of the Certified Benefit Corporations. The method is already in place and the B Lab assessment evaluates the aspects of strong storytelling. The assessment tests, compensation, benefits, training, education, communication, health, and other aspects of employment that guarantee a healthy work environment. The certification is communicating an external benefit. Realistically, the decision to become a Certified Benefit Corporation can allow for good governance practices and if this aligns with your implications for CSR, then the annual fee is a small step to better internal strategies to achieve a business's long term goals of "doing better." 
Adam Lowry and Eric Ryan, the co-founders of Method, an eco-friendly soap product, bring a modern element to a household item. Method's products prevent a list of unpronounceable ingredients from being in the air of homes. The combination of high growth and high impact gives them the ability to be a pristine example of a Certified Benefit Corporation. The best part, Method utilizes their employees (Honeymoon R. 2014). Method is in the top 2\% of B Corps, meaning they are doing things right. Each employee has three paid volunteer days per year, as a form of giving back. It seems as if they all want to do that. Each employee "takes a spin as a receptionist" to ensure there is no miscommunication about the level of each employee's workload and equality in the office space. The team in San Francisco also participates in weekly yoga (Method, 2019). The B Lab takes into account wages, benefits, training/education of the corporation's values and business, worker ownership, manager and worker communication, occupational health, corporate culture. B Lab is guaranteeing if a business has its certification, its employees are going to be treated well (Certification, 2020, n.p.). This connection leads us to the first research question:

RQ1: What internal communication strategies improve employee engagement in CSR initiatives in Certified Benefit Corporations?

\section{Triple Bottom Line in Certified Benefit Corporations}

Fresh Prep, Vancouver's high-ranking meal prep distributor, is a great example of a B Corp that aligns its values with legislation. "Our founders wanted to ensure that no matter who was a shareholder, the values were never in question. Having B Corp certification aligns with the corporation's values and defines what's important, but investors also have to buy into this concept and know that it will work to serve all stakeholders," Fresh Prep's CEO states (Curran, 2019). Fresh Prep believes that its values are even more visible to the public because of the certification through B Lab. Fresh Prep focuses mainly on the environmental impact of the triple bottom line by using local and organic ingredients in their meals. Prioritizing planet over profit leads them to more exposure, which increases brand awareness. Triple bottom line values are essential to B Corps. Managers in both for-profit social benefit corporations and nonprofit organizations face diverse stakeholders, such as donors, investors, communities, beneficiaries, board members, and staff. There is an expectation that managers will share the same values as their diverse stakeholders and subsequently make good decisions in the public interest (Miller-Stevens, 2018). Social entrepreneurs trying to determine whether to achieve their goals by applying for a hypothetical Certified B Corps suggest that nonprofit organizations and benefit corporations are different, but leaders within these corporations who participate reflect the similar ethos of social impact (Miller-Stevens, 2018). The correlation of ethos and impact let stakeholders know that certified benefit corporations and other businesses who participate in CSR value the same things. The following research question is posed:

RQ2: How do triple bottom line values in business models encourage transparency in Certified Benefit Corporations?

\section{CEO Activism and Key Decision Makers in Certified Benefit Corporations}

In terms of organizational structures, becoming a Certified Benefit Corporation is a valued asset to a business model. The key decision-makers, such as the CEO of a company, have a huge impact on the decision to apply or not and using the right evaluation to determine if it is right for their brand to become one. Certified Benefit Corporations are not just for marketing purposes, they accelerate the evolution of capitalism (Honeymoon R., 2014). When analyzing the way 21 st-century business is organized we see they maximize shared value (Honeymoon R., 2014). If $42 \%$ of modern-day consumers care about CSR, then $42 \%$ should care about whether a corporation is a B Corp. We see this through technology and awareness being stronger than ever when most people with a laptop or Shopify account can become an entrepreneur, trusting businesses and their credibility is a new ideology.

Leaders of each certified B Corp are invited to conferences and workshops to form a community. This is completely a choice by key decision makers of the corporation, but the benefits are highly valued by consumers (Storper, 2018). The network the B Lab brings to the small and large B Corps is a resource that can be used for growth, partnerships, and real-life relationships. The following research question is posed: 
RQ3: How do CEOs and key decision-makers in Certified Benefit Corporations encourage the growth of corporate social responsibility internally?

This integrative research review has established that the relationship between internal communications and CSR is proven. Certified Benefit Corporations are possible next steps for corporations who already participate in CSR because the characteristics of internal communications can easily be applied to the application process for a Certified Benefit Corporation.

\section{Methods}

A qualitative methodology was chosen to answer the exploratory research questions proposed in this study. Specifically, in-depth interviews were conducted to allow executives from B Corps in a regional area to discuss CSR and internal communication strategies openly while offering details about employee engagement strategies and challenges. Four companies were randomly chosen from the official B Corp Directory. The official Certified Benefit Corporation website (bcorporation.net) provides a directory showing local participants near the geographical location in which the research was conducted. The number of companies selected was based on company availability and the researcher reaching a saturation point with the overlapping themes and findings from the interviews. The four companies were asked a set of in-depth interview questions and were referred to throughout the paper a Company A, Company B, Company $\mathrm{C}$, and Company D. The interviews were conducted in person, by phone, or by email, with executives with the titles of CEO/Founder of a full-service video production company (A), Creative Director and Co-President of a full-service creative agency (B), B Corp Representative of an investment company (C), and CEO/Founder of a blanket company (D).

Before the interviews, the participants were guaranteed anonymity and told that identifying information would be removed from the study. Generic descriptors, such as a female CEO, are used to preface specific quotations in this article. The participants indicated implied consent and agreed to have the interviews audio recorded. The interview times ranged from 60-90 minutes in length. During the interview, participants were first asked to provide a background on their company and their story on becoming the CEO or key-decision maker. The main interview questions focused on the B Corp's CSR activities, how they define CSR, CSR messaging strategies, and how their commitment to CSR intersects with internal communication and their status as a B Corp. The questions led to open dialogue about the B Corps and the influence they had on the company. Each interview was transcribed accordingly (see Appendix A for a complete list of interview questions)

\section{Results}

Each B Corp exudes the efforts of CSR. Company A donates 1\% of all profits from their company to their foundation that gives back to the community. Company B is a full-service creative agency that helps community-driven brands launch, grow, and meaningfully impact the human experience. Company $\mathrm{C}$ nurtures and develops consumer brands that have a positive impact on the world by advising, investing, and driving ventures with breakthrough sustainable business models. Company D is a sustainable blanket company that is personally branded by the CEO and $10 \%$ of the purchases are donated to domestic violence shelters. The results of the research questions were gathered through a series of questions listed in Appendix A.

RQ1 asked what internal communications strategies improve employee engagement in CSR initiatives in B Corps. Generally, all the participants emphasized supporting and empowering employees to be CSR ambassadors, strengthening company culture, and emphasizing inclusivity.

\section{Internal Communications and Employee Engagement}


Company A is a full-service production company in Tampa, Florida that founded a 501(c)(3) non-profit called the Tampa Foundation which aims to inspire the community through positive, public art. Company A reported each employee receives one paid volunteer day which allows them to give back individually to causes they are passionate about in the community. Additionally, five of their employees serve on the Board for the Tampa Foundation and are involved in all the non-profit's community projects. Company A reported that they best exemplify practices to new employees through model behavior and mentorship while providing a unique opportunity to work directly with senior leadership and often engage employees in team bonding. These experiences strengthen their relationships with each other. Employees internally are encouraged to keep creating outside of work and to use their abilities and passions for good. Several employees who freelance as photographers and musicians represent what Company A stands for as an innovative brand.

Leaders in Company A have always entrusted employees to uphold brand values and share the brand story with others. Part of the strong leadership also includes educating the employees of CSR practices and the purpose behind them, so that they too can be spokespeople of the brand. Company A host's events such as One Table, a seasonal school supply drive when there's an opportunity to make a positive impact. Company A is recognized internationally for its efforts to do good in the world. The executive said, "It's always been important for me to do work that I believe in and give back to the community, so working for a company that provides those things makes me more invested and passionate about coming to work every day." Company A communicated what it means to be a Certified Benefit Corporation to their employees, they made a video that celebrates the certification and educates others on what it means to be a B Corp. The video shared both internally and externally, has helped the team understand the relevance of certification and become educated in speaking into it on behalf of the company. Employees are more conscious of what it means to be sustainable and socially responsible. Several employees have then after, come to executives with ideas about how the brand can align even more with B Corp values. For example, to put people first, the Creative Director suggested that they replace the 'Men's and 'Women's restroom signs with gender-inclusive signs that just say "restroom". A couple of weeks later, the signs were changed. This is just one example of employee ideas that are being adopted every day to improve company culture.

Company B is a creative agency and does not have a specific product they sell, but a service. They offer time and resources to guarantee that the employees are having the best quality of life they can. Each employee can work up to four hours of paid volunteer work half a day every month. Collectively, they do some community-related projects of some sort once a month. The executive stated, "All 26 employees went to Mill Village Farm to teach underprivileged students how to farm. They have also attended a school in Greenville where minorities needed to be read to by university football players in our community. However, we can insert ourselves into the community is how we would give back." The employees made a collective decision to spend a portion of their holiday budget strategically and donated a third to different local nonprofits.

Company $\mathrm{C}$ values company culture by a deep commitment to service and corporate citizenship in their community. They have an ongoing sense of CSR by donating $10 \%$ of all profits to charity and another $10 \%$ to an employee bonus pool. $10 \%$ of investment gains distributed to non-partner employees and partners. All partners of Company C allocate pro-bono advisory time each month and provide service hours to local charities in Raleigh-Durham through their employees.

Company D has a volunteer policy for employees, but they do not dictate where people volunteer. The company allows their employees extra paid time to volunteer and most choose to serve at domestic violence shelters, the initiative behind the company's model. The employees naturally gravitate to this service due to the knowledge they receive from working for this B Corp. The CEO reported, "Every shelter has a different need. The local shelter in Charlotte needs help specifically with donations, others may need someone to teach a class, Company D makes sure they are giving back what a shelter needs, not just the same standard gift." The volunteer days are logged on a shared excel sheet. They have 3 interns, 3-4 employees in the warehouse in Spartanburg, South Carolina, 3-4 people who do different projects seasonally, and 2 constant employees in addition to the CEO. They mainly work from a coworking space membership, but remote employees in Miami and Georgia make sure to video chat for weekly team meetings. 
Remote employees make it accessible to serve different communities for Company D. The executive said "We put together a brand style guide. Giving employees a reign of creativity and flexibility. The marketing employee took it upon herself to create a style guide, so our brand is cohesive. We love them!" Company D also participates in popups. For example, West Elm local is something they have done where they have been set up before. Their new initiative allows for survivors to become an employee all across the globe. Anyone can sign up and decide to sell blankets and receive a commission from them. The brand uses this tool to empower customers and make them feel as if they are working in this community.

The results of the second research question showed that triple bottom line values in each of the four companies give them a sense of transparency.

\section{The Triple Bottom Line and Transparency}

Company A's tagline is, 'Video as a force for good,' because they are dedicated to using video to tell stories that matter and make a positive impact in our community. This mission statement shows what sustainability means to be able to exist constantly with minimal or no harm to the environment and future generations. This company reports that therefore they are mindful of waste and usage. For example, they recently revamped the office space to be ecofriendly by installing a water bottle refill station, automatic hand dryers, and energy-efficient LED light bulbs. The company recycles any old equipment and disposes of lightbulbs, batteries, and other harmful waste properly. According to the executive, the mission statement, 'Video as a force for good' itself embodies the commitment to sustainability and social responsibility by confirming the promise to use the brand for good. The executive stated, "profit has never been the driving force in our company." They were founded on purpose; the purpose is to tell stories that matter and to use video as a force for good. The executive continued, "Consumers are very impressed to learn of the B Corp Certification. Only a select few are familiar with B Corp so it's exciting to share that process as part of our brand story and relate it to our values and mission."

Company B chooses to give local organizations a discount for their agency. A couple of years back, the agency did a pro bono foundation marketing plan for "THE VILLAGE" employees, a local nonprofit, and offered 6 months of free social media work. The executive said, "To us, sustainability means to be able to exist constantly with minimal or no harm to the environment and future generations." It was communicated that they are working on that product with a sustainable zero carbon footprint, right now the brand is not producing a product, they are producing mainly digital content. The co-president said, "We do small things in the office like recycling, but mainly we are focused on the sustainability of employees. We have thought about doing the branding for those who have thought about creating a sustainable product, you know how we take that extra jump." If the future of sustainability is branding in the identity of work, you need help telling that story messaging to the world. From branding and identity development to experiential activation, community management to word-of-mouth marketing strategies, they partner with brands and organizations that believe in doing something worth talking about.

Company $\mathrm{C}$ nurtures and develops consumer brands that have a positive impact on the world. They advise, invest in, and incubate mission-driven ventures with breakthrough sustainable business models. Having multiple entities and hierarchies of employment makes it crucial for strong internal communications. Their mission statement is "Do well. Do good. Do One Better." The clients who either are B-Corps or could be B-Corps if they went through the formal certification process. Company $\mathrm{C}$ believes in the Triple Bottom Line that is the core of this question (people, planet, profit). While there are examples of environmental friendliness and social justice in many of their portfolio companies, the common thread through them all is health and wellness. From sleep to diet (ketogenic, JERF, kombucha), to herbal supplements (including CBD), and air purification, all of the companies deliver healthier solutions and are typically natural, organic, and toxin-free meeting B Corp economic standards.

The CEO of Company D decided to sell blankets and donate the funds to specific items that domestic shelters.org requested. Why a blanket? The CEO wanted to empower survivors to share their stories. The CEO took her trauma and decided to turn it into a business. The names of the blankets are confidence, love, and serenity. Designed 
purposefully for comfort to the customers. When it came to triple bottom line values, the entrepreneur had a list at first of wanting to meet ethical and sustainable standards to align with a B Corp. The CEO wanted the best blanket, the best relationship with her employees, and the best impact. The CEO said, "I chose my manufacturer because of their philosophy on the environment. They are all Global Organic Textile Standard Certified which is 100 percent organic cotton. So, from the fibers of the blanket to the tag, everything is made with clean chemicals and materials." A B Corp can't be certified until you are a year old, and the CEO achieved the B Corp pending certification with this in mind. B Corp approved her as pending until Company D turned a year old, then she went through the official assessment. The CEO reported, "We are people-based. People buy our blankets because they want to give back or they want to give this to someone because they know it is important to them. I joke about how I could be selling anything, but the fact it is a sustainable product gives the extra meaning and purpose."

The third research question explores the topic of CEOs and key decision-makers in businesses that value CSR and encourage growth in Certified Benefit Corporations.

\section{Key Decision Makers and Networking}

Company A defines itself as a family, so many times people become advocates for new ideas and get the opportunity to grow into leaders. Several team members have influenced this company's employees by introducing new ideas and getting the rest of the team on board. An example mentioned, a product in the office recycling program, which was implemented after several team members championed it. The senior leaders are great at living for the company values and sharing the brand story in their personal lives. The founder and CEO, for example, often uses keynote speaking opportunities to explain the brand purpose and advocate for other companies to become B Corp certified and adopt stronger practices. Becoming a B Corp was a huge milestone for this company, but there's always the opportunity for growth in this area, as well as others, and they are continually looking for opportunities to expand different forms of CSR and outreach. A staff member said, "We highly value communication. Being such a small team, everyone has a role in many aspects of the business so it's important for everyone to be on the same page. We also do a high volume of work and need to be as effective and efficient as possible; we've found communication is key in executing big ideas and staying true to our brand. We have already received some outreach from other B Corps who want to work with us just because we are a B Corp."

Company B attends a fun diversity inclusion event every month at local restaurants. The co-president said, "With being in South Carolina, there are not as many B Corps, I am trying to connect with the North Carolina B Corps. I have a partnership with the co-president to partner with the B Corporation Summit \& other regional groups. B Corp is mostly female so I am a part of 'B the change' where we have collected a group where women can cross value each other and find a stronger place in a financial standpoint." She spoke on how her influences from other B Corps, podcasts, and webinars have influenced her leadership style and excitement to pour out to her team. Internally Company B has positive energy and communicates digitally via email, phone, and meets once a week physically. The copresident explained the importance of a positive work environment and how transparent values painted on murals in the office provide a great office culture. In terms of structure, the leadership starts with the co-presidents, then a leadership team. The company is new, during the new business stage they were also using the B Corp as a part of their brand identity. This identity has been helpful for the business for the past few years. One staff is specifically dedicated to handling the B Corp communications and ensures that they are meeting each requirement. They have been a B Corp if they have been a business. All employees are like-minded and have the same end goal. All the B Corp requirements are made aware to employees, and it is another way to be accountable other than our clients. The co-president stated, "We have authentic employees that will call you out if you are not meeting a requirement. B Corp is going to continue to kill it. With the expansion of that option, our business will grow with it. We have been open to a group team of B Corp advertising to our employees. We have already received some outreach from other B Corps who want to work with us just because we are one!"

Company $\mathrm{C}$ has five equal partners, three staff, and several interns. They are a flat organization who work in one room together and share information freely. They have a weekly staff meeting with all employees and monthly 
partners. Virtually every document resides in a shared drive that all employees can access. The CEO is a leader in the conscious consumer and mission-driven brand movement, with extensive experience leading fast growth, high-performing businesses including Seventh Generation and Burt's Bees. The CEO believes that business is one of the most powerful forces on earth and that power must be harnessed for the greater good. The focus is on growth strategies, organizational and cultural design, mission and values, and CEO coaching. The reason these executives like the BCorp certification is because it is a formal alliance with other businesses that are modeling ethical and progressive behaviors. The rigor of the certification process and the bi-annual recertification ensures minimum standards are met. To this company, B Corp gives a sense of improvement overtime on things that they want to do better. Executives said, "It ensures they are 'walking not just talking'. We mostly value networking and collaboration with other B-Corp companies, we haven't quite been able to use it with our consumers. The process does require some time and money, but it is good value overall."

Company D values the idea of a spokesperson. The CEO is a part of the brand image. The story is about the seller of the product. The CEO stated, "Some of my employees happen to be survivors, you know they are relating to the mission, and I love that we give them a platform to share their story. We have grown so much in the past year because of our new initiative. I was the first one to open up, and now employees and customers are both sharing stories of domestic violence and finding a community." For example, she shared a story of someone who saw their product on a friend's couch and asked where they had purchased it. This opened a whole conversation about how they were in an abusive relationship. The blanket started a conversation about something the person had never spoken about before. The CEO explained her B Corp process., "On the website, they have an assessment. You can take this to see where you land, and you must score a certain percentage. We are in the top 10 percent because we wanted to make sure we were doing things right and we still have room for growth. You may qualify and not realize it. Many companies could make minor changes and reach this certification. Now that we are certified, people are finding us in the B Corp directory for partnerships, relationships, and new customers, I mean it is how you found me!"

\section{Discussion}

The three research questions proposed stories, personal conversations, and the ability to acknowledge the growth of Certified Benefit Corporations. The researcher has gathered three common themes from the questions to discuss to reflect this integrative literature review that has established the strong, positive relationship between internal communications and CSR. Are Certified Benefit Corporations a possible next step for corporations who already participate in CSR because the characteristics of internal communications can easily be applied to the application process for a Certified Benefit Corporation?

Corporate storytelling and creating an environment where the employee can be a champion for the brand is a crucial part of being a Certified Benefit Corporation. First, Company A created a unique opportunity for all employees mentored by senior leadership and often engaged employees in team bonding. These experiences strengthen their creativity internally and externally. Externally, the paid volunteer days have translated to experiences of creativity and giving back outside of Company A in their personal life. Internally, responses from office behavior such as changing the bathroom sign to include all genders create an environment where employees feel heard. This same energy is apparent in Company B where paid volunteer days, encouraged by the B Impact Assessment (BIA), are crucial. The donation of their Christmas party funds aligns with B Corp values. Group volunteering is also a great way for these offices to feel connected internally and with their community. Company B and Company $\mathrm{C}$ offer pro bono work for their local community nonprofits, this is a great way to build up trust. Company $\mathrm{C}$ delegates 10 percent of earnings to an employee bonus pool. Company D does a fantastic job at the employees being advocates for their values. A trailblazer program is a tool that allows the company to give a platform to all sorts of survivors to be an employee. As employees naturally gravitated to work for the company because they wanted to help with domestic violence, their service began there. The CEO made it a point to discuss that their volunteer days go beyond domestic violence, as they participate in other community needs as well. Taking care of your employees financially and socially stems back 
to what was discussed about creating an environment where your employee is satisfied to be a part of a company. Corporate storytelling is a persuasive, natural, and simple way to communicate a message within a business. Corporate storytelling is the ideal way of making the employee a champion of your company (Duthler, G., \& Dhanesh, G. S., 2018). The employees, especially in Company D, identify and tell the story of the brand. With incentive beyond the average, your employee is going to be an advocate for working for the brand and the same values your brand holds. In addition to feeling good about who your company is, B Lab guarantees that their companies are going to be treating their employees well and the certification justifies that storytelling of employees (Certification, 2020, n.p.).

The third-party validation that comes with B Corp Certification helps your company stand out and stand by your mission. The B Corp seal on a product, website, sales materials or business card instantly communicates that a company is a verified leader when it comes to positive impact and empowers individuals to confidently vote with their dollars (Certification, 2020, n.p.). Each corporation has a second theme of creating a mission that aligns with more than one part of the triple bottom line. The triple bottom line is a crucial part that translates to the B Corp model of valuing people, planet, and profit. Each company integrated the clarification of a value set in the mission and vision statements during the strategic planning process of a business model (Miller-Steven, 2018). Company A creates initiatives in the office to be eco-friendly, meeting the environmental factor, and the fact they were founded on the purpose to tell a story shows their model around people. Company B naturally meets environmental standards by being a completely digital company but discussed taking steps for administration and energy levels to be sustainable. The executive-created conversation around making the length of their employee life sustainable is something that shows the dedication of the B Corp model. Company B is currently looking to dedicate its service to reach clients with sustainable products or services. This is the perfect example of how B Corps are thinking beyond the minimum to reach the Triple Bottom Line. Company $\mathrm{C}$ created a network for health and wellness companies and only invests in brands that match their mission. According to this statement, for companies to already be integrating this into their business model, this research shows a great deal of evidence to integrate a BIA. Company D locally sources its manufacturers to maintain a sustainable product that matches B Corp, in addition to creating a sense of community for people. Having their product be organic down to the print on the tag, meaning no harm is done to the environment or their employees is a great example of the triple bottom line. Each of these companies is constantly striving to meet all three factors of the triple bottom line and the B Certification only provides a credible source to prevent greenwashing.

Lastly, a common theme found was the B Corp allowed these for-profit companies a community and network. According to B Lab, "B Corps form a community of leaders and drive a global movement of people using business as a force of good. The values and aspirations of the B Corp community are embedded in the B Corp Declaration of Independence" (Certification, 2020, n.p.). Essentially, these B Corps are created for the sole purpose of having a general sense of "good" come out of businesses rather than from the government and nonprofits. This can be directed back to the concept of CSR. This research directly interviewed CEOs and executives, as these are the ones with the story behind the brand. The entrepreneurs who came up with their business idea, the real people behind the purpose of essentially running a business to create a profit for good. What does B Corp do? It allows these leaders to connect. The leaders from Company A, Company B, Company C, and Company D have all been able to create a network with other B Corps and further partnerships, and who knows, maybe connect? The B Corp directory online is a resource for connections, but it doesn't end there. Certified Benefit Corporations are not just for marketing purposes, they accelerate the evolution of capitalism (Honeymoon R. 2014). This research proves this statement, the consumers have spoken to want more attached to their purpose and voting with a B Corp is one of the best ways to do so in 2020.

The three themes discovered through these interviews all suggest how the strong internal communications of a company can be represented in a Certified Benefit Corporation. This research can be used to suggest a further expansion of B Corps with companies that may qualify without even knowing it. Future research may examine the reasoning of an obvious contrast in small businesses and big corporations applying to become a B Corp. Specifically, the research may explore the connection between business size and the demographics of consumers who are attracted to the companies that value CSR. 


\section{Conclusion}

In conclusion, findings from this study suggest that companies with strong CSR should have strong internal communications to further create a culture that embraces social responsibility. Internal communication emphasizing corporate storytelling can engage employees into becoming advocates for CSR. In addition, if a business with the same storytelling methods becomes a Certified B Corp, they must maintain the structures but to a higher standard as they are assessed on this strategy to qualify. Internal communications also weave in values of CSR to the message of their brand. In addition, if a business with the same values becomes a Certified B Corp, then the values become clearer because the triple bottom line is present in B Lab qualifications. Lastly, key decision-makers who are already engaging in CSR by practicing strong internal communications have an opportunity to switch from consciousness to legal binding with Certified Benefit Corporations.

\section{Limitations}

The research was done through the University of South Carolina as an independent research project. Due to limited resources, 4 CEO's were interviewed in the southeast to gather primary research. This limited the variety of perspectives, yet still offered valuable insight for different types of Certified Benefit Corporations. Conclusions were drawn through proximity using the database of all Certified Benefit Corporations on https://bcorporation.net/.

\section{Acknowledgements}

I would like to thank Dr. Holly Overton for mentoring me throughout the primary research of this project. Dr. Overton was appointed as a Senior Research Fellow with the Arthur W. Page Center for Integrity in Public Communication (2020-2024) and is an incredible professor at the School of Journalism and Mass Communications at the University of South Carolina. Thank you, Dr. Overton, for exceeding any expectations with mentorship and being the best possible resource for research in our field. I would like to appreciate Dr. Sharon White for leading the Ronald E. McNair Program for first-generation college students at the University of South Carolina. Thank you for pushing each of us in the direction of research and higher education. Lastly, I would like to thank the Magellan Program at the University of South Carolina for encouraging beyond the classroom learning and independent research projects.

\section{References}

(2018, July 11). 5 Business Management Strategies We Learned as a B Corp. Retrieved from Web. https://bthechange.com/5-business-management-strategies-we-learned-as-a-b-corp-42e91639c6ae

Ashforth, B.E., \& Mael, F. (1989). Social Identity Theory and the Organization. Academy of Management Review, 14(1), 20. https://psycnet.apa.org/doi/10.2307/258189

Bowden, J. (2009). Customer Engagement: A Framework for Assessing Customer-Brand Relationships: The Case of the Restaurant Industry. Journal of Hospitality Marketing \& Management, 18(6), 574-596.

https://doi.org/10.1080/19368620903024983 
Benton, R. (2002). Environmental Racism, Consumption, and Sustainability - Faces of Environmental Racism: Confronting Issues of Global JusticeLaura Westra and Peter S. Wenz, Editors Lanham, Md.: Rowman \& Littlefield Publishers, Inc., 1995 - The Business of Consumption: Environmental Ethics and the Global EconomyLaura Westra and Patricia H. Werhane, Editors Lanham, Md.: Rowman \& Littlefield Publishers, Inc., 1998. Business Ethics Quarterly, 12(1), 83-98. doi:10.2307/3857650

Certification. 2020. https://bcorporation.net

Chatterji, A. K., \& Toffel, M. W. (2019). Assessing the Impact of CEO Activism. Organization \& Environment, 32(2), 159-185. https://doi.org/10.1177/1086026619848144

Cherry, M. A., \& Sneirson, J. F. (2011). Beyond profit: Rethinking CSR and greenwashing after the bp oil disaster. Tulane Law Review, 85(4), 983-1038. doi: 10.2139/ssrn.1670149

Cone (2013). 2013 Cone Communications Social Impact Study: The Next Cause Evolution. https://www.conecomm.com/research-blog/2013-cone-communications-social-impact-study

Cone, L. (2006, October 24). Civic-Minded Millennial Prepared to Reward or Punish Companies Based on Commitment to Social Causes. Accessed 14 September 2010. https://www.csrwire.com/press releases/19346-civic-mindedmillennials-prepared-to-reward-or-punish-companies-based-on-commitment-to-social-causes

Connelly, B. L., Certo, S. T., Ireland, R. D., \& Reutzel, C. R. (2011). Signaling Theory: A Review and Assessment. Journal of Management, 37(1), 39-67. https://doi.org/10.1177/0149206310388419

Chen, X., \& Kelly, T. F. (2015). B-Corps-A Growing Form of Social Enterprise: Tracing Their Progress and Assessing Their Performance. Journal of Leadership \& Organizational Studies, 22(1), 102-114.

https://doi.org/10.1177\%2F1548051814532529

Duthler, G., \& Dhanesh, G. S. (2018). The role of Corporate Social Responsibility (CSR) and internal CSR communication in predicting employee engagement: Perspectives from the United Arab Emirates (UAE). Public Relations Review, 44(4), 453-462. doi: 10.1016/j.pubrev.2018.04.001

Elkington, J. (1999). Cannibals with Forks: The Triple Bottom Line of 21st Century Business. Oxford, the UK: Capstone Publishing Limited. http://www.trentglobal.edu.sg/wp-content/uploads/2017/01/Triple-Bottom-Line.pdf

Giddens, Michele. “The Rise Of B Corps Highlights The Emergence Of A New Way Of Doing Business.” Forbes, Forbes Magazine, 6 Aug. 2018. https://www.forbes.com/sites/michelegiddens/2018/08/03/rise-of-b-corps-highlights-the-emergence-of-a-new-way-of-doing-business/?sh=a95ef1f2ed29

Hutton, J. G., Goodman, M. B., Alexander, J. B., \& Genest, C. M. (2001). Reputation management: The new face of corporate public relations? Public Relations Review, 27(3), 247-261. doi: https://doi.org/10.1016/S0363-

$8111 \% 2801 \% 2900085-6$

Katz, N. "What Is Sustainability?” UCLA Sustainability. (2019). Retrieved from www.sustain.ucla.edu/what-issustainability/ 
Keller, K., Aaker, D. The Impact of Corporate Marketing on a Company's Brand Extensions. Corp Reputation Rev 1, 356-378 (1998). https://doi.org/10.1057/palgrave.crr.1540057

Method. People Against Dirty. 2019. Retrieved from https://methodhome.com/

Miller-Stevens, K., Taylor, J. A., Morris, J. C., \& Lanivich, S. E. (2018). Assessing Value Differences Between the Leaders of Two Social Venture Types: Benefit Corporations and Nonprofit Organizations. Voluntas: International Journal of Voluntary \& Nonprofit Organizations, 29(5), 938-95.

https://doi.org/10.1007/s11266-017-9947-9

Mull, Amanda. "Fashion's Racism and Classism Are Finally Out of Style." The Atlantic, Atlantic Media Company, 7 July 2020. https://www.theatlantic.com/health/archive/2020/07/fashions-racism-and-classism-are-going-outstyle/613906/

Schaefer, S.D., Terlutter, R., \& Diehl, S. (2019). Talking about CSR matters: employees' perception of and reaction to their company's CSR communication in four different CSR domains, International Journal of Advertising, 39(2), 191-212. https://doi.org/10.1080/02650487.2019.1593736

Storper, Jonathan. "What's the Difference Between a B Corp and a Benefit Corporation?" Conscious Company, 11 July 2018. https://doi.org/10.1080/19420676.2019.1624273

Pompper, D. (2018). CSR, Sustainability, and Ethical Public Relations: Strengthening Synergies with Human Resources. Bingley, UK: Emerald Publishing Limited. www.emeraldinsight.com/doi/book/10.1108/9781787145856

Woodward-Clyde (N.Z.). (1999). Key opportunities and risks to New Zealand's export trade from green market signals: Final paper. Auckland, N.Z: Woodward-Clyde. 